\title{
Open access clinic providing HIV-I antibody results on day of testing: the first twelve months
}

\author{
S B Squire, J Elford, R Bor, G Tilsed, H Salt, E K Bagdades, G Janossy, P D Griffiths, \\ M A Johnson
}

\begin{abstract}
Objectives-To determine the sociodemographic profile, risk category, and prevalence of HIV-I infection among people attending a clinic providing counselling, medical advice, and results of HIV-I antibody testing on the day of consultation; to determine the stage of infection and peripheral blood CD4 cell count among attenders with detectable HIV-I antibodies.

Design-Analysis of prospectively collected data for the 12 months from March 1989.

Setting-Same day testing clinic run by the HIV/AIDS team at an urban teaching hospital.

Patients -561 consecutive people choosing to attend and proceeding to HIV-I testing.

Results-The demand for the service caused it to run to capacity within six months. The median age of those attending was 28 years and $65 \%$ (364 patients) were male. The overall prevalence of HIV-I infection was $3.9 \%$ ( 22 patients). The greatest prevalence was in men reporting their primary risk as homosexual contact $(11.9 \%, 13 / 109)$. The median CD4 cell count in the 22 patients who had detectable HIV-I antibodies was $0.31 \times 10^{\circ}$ cells/l (normal range $0.5 \times 10^{9} / 1$ to $\left.1.2 \times 10^{9} / 1\right)$. Twenty of these patients were asymptomatic (Centers for Disease Control stages II or III), 14 had CD4 cell counts below $0.5 \times 10^{9} / 1$.
\end{abstract}

Conclusions - There is a recognisable demand for a service providing rapid results of HIV-I antibody testing in this setting. The overall seroprevalence of $3.9 \%$ is comparable with the $5.8 \%$ reported from freestanding clinics in the United States. Most patients with HIV-I antibodies detected in this way are asymptomatic but could benefit from early medical intervention because of low CD4 cell counts.

\section{Introduction}

Immunoassays are widely used to detect antibodies to HIV-I in serum samples and are accepted arbiters in determining whether or not an individual has been infected with HIV-I. ${ }^{1}$ Most asymptomatic people infected with HIV-I will go on to develop AIDS, but the incubation period is variable, with a mean of 10 years and a range of 2-20 years. ${ }^{2}$ The social and emotional disadvantages of discovering a positive result of HIV antibody testing may be devastating, but there is increasing evidence that early medical intervention in the course of the infection is an advantage and will improve the outlook for infected patients. ${ }^{3.5}$ Those who come forward to be tested for HIV antibodies need up to date information and have to balance the advantages and disadvantages of knowing whether or not they have been infected before deciding finally to be tested. Counselling is clearly important in this decision making.
Our experience suggests that once the decision to be tested has been made and the necessary blood sample taken, most people experience enormous anxiety while waiting several days or even weeks until a result is known. Other sources of anxiety include concerns about confidentiality, reliability, and availability of medical knowledge of HIV and AIDS should the result prove positive. To reduce this anxiety and to provide up to date information on HIV infection we have established an open access, confidential clinic that gives results of HIV-I antibody tests within seven hours on a specified day each week. The clinic is staffed by trained counsellors, nurses, and doctors of the designated HIV and AIDS team under the consultant physician in HIV and AIDS, and there is close liaison with the staff of the diagnostic laboratory. We report our experience in the first year.

\section{Methods}

An overview of the organisation of the clinic is given in figure 1. The clinic telephone number was made available to the voluntary organisations concerned with AIDS and HIV, and appointments were made by telephone through the AIDS counselling service. All calls were taken by experienced counsellors, who discussed with the caller some of the issues surrounding an HIV test and made an assessment of the relevance of HIV testing in each case. When more extensive counselling was thought necessary appointments were made for counselling sessions alone.

Most appointments were booked directly for between 9 am and 11 am on the morning of the clinic. Details of the telephone conversations were noted on customised record forms, which were used again on the day of HIV testing.

A doctor and a counsellor together saw each patient to discuss all the issues surrounding the HIV test. It was emphasised that only HIV testing would be carried out; if concerns about other sexually transmitted diseases were raised patients could be referred to the adjacent clinic for sexually transmitted diseases.

Data were recorded on forms designed for the clinic. If risk factors for HIV-II infection were identified the patient was informed that testing for both HIV-I and HIV-II would be carried out but that only the results for HIV-I would be available on the day of the clinic and that results of the HIV-II assay would not be available for three weeks.

If the patient decided to proceed to HIV-I testing $10 \mathrm{ml}$ of clotted venous blood was taken by the clinic nurse. The patient was told that the result would be available at $4 \mathrm{pm}$ that afternoon only to the patient in person and that as the patient returned for the result he or she would be told the result immediately. Patients were advised that their blood test would give one of three possible results.

Correspondence to:

Dr Squire. 


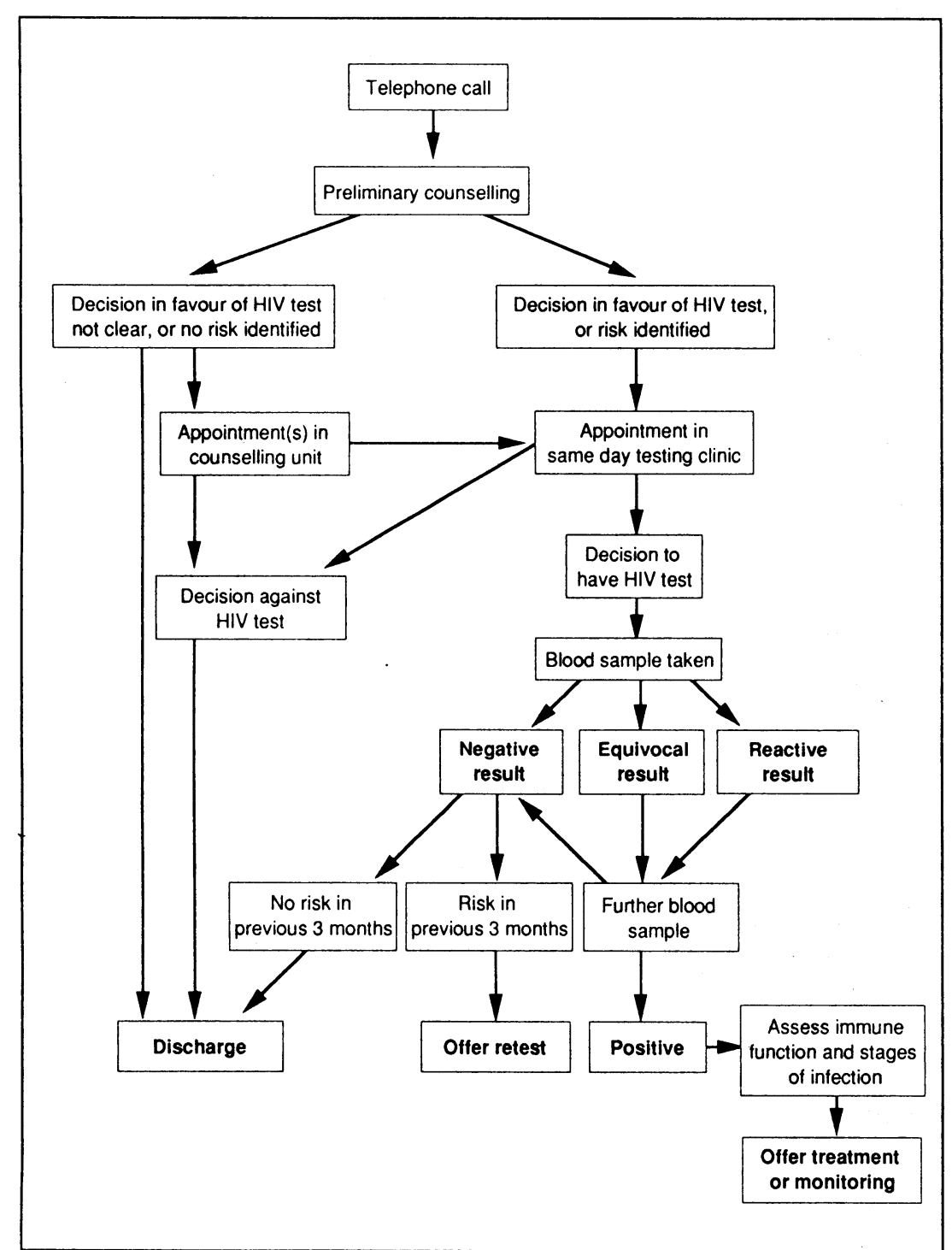

FIG 1-Organisation of same day HIV testing clinic
(1) A "reactive" result would mean that one assay had indicated that antibodies to HIV were present in the blood sample. Before this could be confirmed as a true positive result the blood would be tested by a total of three assays and a second blood sample should also be positive. If the blood was reactive a second blood sample would be taken on the afternoon of the clinic and all results would be available 48 hours later. It was emphasised that the supplementary assays and the second blood sample were seen as confirmatory and could be expected to prove reactive in most cases. In addition, for patients with a reactive result a full medical history and examination followed by appropriate medical investigation, including serological screening for latent or previously unrecognised infections such as syphilis and hepatitis B, CD4 cell counting, and HIV antigen estimation would be offered, and these results would be available 48 hours later. All patients with reactive results were offered medical and counselling follow up either at this hospital or at an appropriate referral centre closer to their home.

(2) A "negative" result would indicate the absence of HIV-I antibodies. If there had been no possible exposure to HIV-I in the preceding three months this result could be taken to exclude HIV-I infection. If a recent exposure had occurred then additional blood collection and testing would be recommended at times appropriate for each patient.

(3) An "equivocal" result would indicate that the assay had not given a clear cut answer. This might indicate that low levels of antibody were present (for example, soon after seroconversion) or it might indicate a technical error in the processing of the sample, or simply that the sample value fell too close to the cut off defined statistically for that assay. It was emphasised that equivocal results occurred only rarely and would be investigated by collecting further blood for HIV testing, including testing by other methods.

After the explanation patients were given time to raise questions before verbal consent was sought and the blood sample collected. As far as possible patients returning for a result were seen by the same doctor and counsellor as before. Patients were asked if they were satisfied with the service and whether they would make suggestions for improvement. In addition, records were kept on the main reason for patients choosing this service in particular. Emphasis was placed on discussions about risk reduction at the counselling sessions before and after the test regardless of the result of testing.

The assay used to screen the samples for antibodies to HIV-I was the Wellcozyme HIV recombinant assay (Wellcome Diagnostics). It is a competitive enzyme immunoassay utilising HIV-I core and envelope antigens and is prepared by recombinant DNA techniques from HIV-I virus. If the results of this screening assay were reactive both serum samples were retested by this assay. In addition, the original serum was tested with two other assays for HIV antibodies (Abbott recombinant non-competitive HIV-I Enzyme Immunoassay, Abbott Diagnostics, and Serodia HIV particle agglutination test, Mast Diagnostics) and HIV antigens were measured by enzyme immunoassay (Abbott Diagnostics).

CD4 cell counts were obtained using a whole blood method on a FACScan (Becton-Dickinson) as described previously. ${ }^{6}$

Patients' characteristics were prospectively recorded and the results were collected and analysed after 12 months. As the population of clinic attenders was described without formal testing of a hypothesis, no formal statistical tests were performed.

\section{Results}

In all, 565 people attended the clinic during the first 12 months. Four patients were considered not to have any discernible risk for HIV infection. The study population therefore consisted of 561 people. Twice as many men as women attended (364 $v 197)$. None of the clinic attenders was thought to have had significant risk for HIV-II. Increasing numbers attended the clinic over the 12 month study period (fig 2 ). The three month moving average increased from 15 to 71 attenders over the year. The clinic was running to capacity six months after starting, and demand has continued to grow. Data on patient satisfaction and reason for attendance were available on 537 attenders: 530 of these $(99 \%)$ were satisfied with the service and

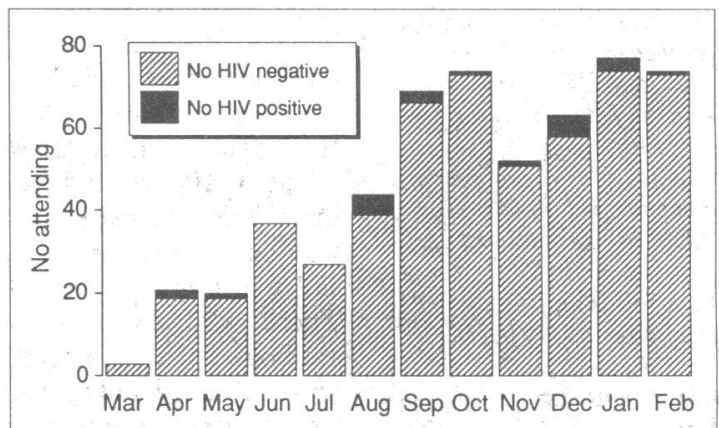

FIG 2-HIV antibody test results of attenders at open access clinic in its first year of operation 
had no suggestions for how it could be improved; 502 $(93 \%)$ patients said they chose the service particularly because of the speed of availability of the results once the blood samples had been taken. All patients were offered an appointment within a week of the initial telephone conversation, but some patients chose appointments at a greater interval for their own convenience.

The median age of those tested was 28 years; $70 \%$ $(393 / 561)$ were between the ages of 20 and 34 years. Data on social class were available from $451(80 \%)$ of the records and showed that $64 \%$ (289) were in non-manual classes, $15 \%(66)$ were in manual classes, and $21 \%$ (96) were students, unemployed, or housewives. Addresses were not recorded in $56(10 \%)$ of the records, but only 76 of those with a recorded address were from within the local health authority boundaries (table I).

Overall, $3.9 \%(22 / 561)$ of attenders were HIV-I reactive on the first screening test, with a seroprevalence of $5 \cdot 5 \%(20 / 364)$ in men and $1 \cdot 0 \%(2 / 197)$ in women. All of these reactive test results were confirmed as positive by all of the supplementary assays used. During the study period only five subjects had an equivocal result on the screening test, due in each case to the value lying close to the cut off; all were subsequently proved negative on retesting and by the confirmatory assays. When analysed according to the presenting risk, the highest seroprevalence of HIV-I was among homosexual men $(12 \% ; 13 / 109)$ and intravenous drug users $(20 \% ; 3 / 15)$ (table II). None of 172 women reporting only heterosexual risks tested positive compared with two of the 212 men reporting a primary heterosexual risk. Additional risks were identified among the 212 men presenting with a heterosexual risk: 12 reported sexual contacts in Africa (including the two who tested HIV positive), six had injected drugs, and nine had received blood transfusions. Of the 172 women presenting with a heterosexual risk, four reported sexual contacts in Africa, nine had injected drugs, and six had received blood transfusions. Of the 109 men with a homosexual risk, four had injected drugs, three reported sexual contacts in Africa, and two had received a blood transfusion.

Table III shows the CD4 cell counts at presentation and the presenting risk of the 22 patients who were positive for antibodies to HIV-I. The median CD4 cell count in these patients was $0.31 \times 10^{9} / 1$ (normal range

TABLE I - Place of residence of those attending a same day testing clinic for $H I V$

\begin{tabular}{lcc}
\hline & $\begin{array}{c}\text { No (\%) of } \\
\text { attenders }\end{array}$ & $\begin{array}{c}\text { No HIV } \\
\text { positive }\end{array}$ \\
\hline Hampstead health district & $76(14)$ & 4 \\
Other London & $330(59)$ & 15 \\
United Kingdom (outside London) & $93(17)$ & 3 \\
Outside United Kingdom & $6(1)$ & 0 \\
Not known & $56(10)$ & 0 \\
\hline Total & $561(100)$ & 22 \\
\hline
\end{tabular}

TABLE II - Risk categories of those attending a same day testing clinic for HIV

\begin{tabular}{|c|c|c|c|c|c|c|}
\hline & \multicolumn{2}{|c|}{ Men } & \multicolumn{2}{|c|}{ Women } & \multicolumn{2}{|c|}{ Total } \\
\hline & $\begin{array}{l}\text { No reporting } \\
\text { risk }\end{array}$ & $\begin{array}{l}\text { No HIV } \\
\text { positive }\end{array}$ & $\begin{array}{l}\text { No reporting } \\
\text { risk }\end{array}$ & $\begin{array}{l}\text { No HIV } \\
\text { positive }\end{array}$ & $\begin{array}{l}\text { No reporting } \\
\text { risk }\end{array}$ & $\begin{array}{l}\text { No HIV } \\
\text { positive }\end{array}$ \\
\hline Heterosexual contact & 212 & 2 & 172 & & 384 & 2 \\
\hline Homosexual contact & 109 & 13 & & & 109 & 13 \\
\hline Bisexual contact & 27 & 3 & 8 & & 35 & 3 \\
\hline Injecting drugs & 8 & 1 & 7 & 2 & 15 & 3 \\
\hline Blood transfusion & 1 & 1 & 2 & & 3 & 1 \\
\hline Occupational & 3 & & 2 & & 5 & \\
\hline Other & 3 & & 5 & & 8 & \\
\hline Total & 363 & 20 & 196 & 2 & $559^{\star}$ & 22 \\
\hline
\end{tabular}

«Data missing for two subjects.
TABLE III - Details of patients at same day testing clinic positive for $H I V-I$ ranked according to CD4 cell count at presentation

\begin{tabular}{lcclcc}
\hline $\begin{array}{l}\text { Patient } \\
\text { No }\end{array}$ & Sex & $\begin{array}{c}\text { Age } \\
\text { (years) }\end{array}$ & Risk category & $\begin{array}{c}\text { CD4 cell } \\
\text { count } \\
\left(\times 10^{4} / 1\right)\end{array}$ & $\begin{array}{c}\text { Centers } \\
\text { for Disease } \\
\text { Control stage }\end{array}$ \\
\hline 1 & $M$ & 24 & Homosexual & $1 \cdot 09$ & III \\
2 & $\mathrm{M}$ & 25 & Homosexual & $1 \cdot 05$ & II \\
3 & $\mathrm{M}$ & 23 & Bisexual & $0 \cdot 61$ & II \\
4 & $\mathrm{~F}$ & 31 & Injecting drugs & $0 \cdot 61$ & III \\
5 & $\mathrm{M}$ & 47 & Heterosexual & $0 \cdot 52$ & III \\
6 & $\mathrm{M}$ & 26 & Homoesexual & $0 \cdot 51$ & III \\
7 & $\mathrm{M}$ & 24 & Homosexual & $0 \cdot 48$ & III \\
8 & $\mathrm{M}$ & 24 & Bisexual & $0 \cdot 39$ & III \\
9 & $\mathrm{M}$ & 38 & Bisexual & $0 \cdot 34$ & III \\
10 & $\mathrm{M}$ & 21 & Homosexual & $0 \cdot 34$ & III \\
11 & $\mathrm{M}$ & 27 & Injecting drugs & $0 \cdot 32$ & II \\
12 & $\mathrm{M}$ & 27 & Homosexual & $0 \cdot 30$ & III \\
13 & $\mathrm{M}$ & 40 & Homosexual & $0 \cdot 30$ & III \\
14 & $\mathrm{M}$ & 26 & Homosexual & $0 \cdot 25$ & III \\
15 & $\mathrm{M}$ & 39 & Homosexual & $0 \cdot 25$ & II \\
16 & $\mathrm{M}$ & 32 & Homosexual & $0 \cdot 23$ & III \\
17 & $\mathrm{M}$ & 19 & Homosexual & $0 \cdot 22$ & II \\
18 & $\mathrm{~F}$ & 34 & Injecting drugs & $0 \cdot 22$ & III \\
19 & $\mathrm{M}$ & 36 & Blood product & $0 \cdot 12$ & IV \\
20 & $\mathrm{M}$ & 41 & Homosexual & $0 \cdot 11$ & II \\
21 & $\mathrm{M}$ & 42 & Homosexual & $0 \cdot 06$ & IV $\dagger$ \\
22 & $\mathrm{M}$ & 34 & Heterosexual & $0 \cdot 003$ & III \\
\hline
\end{tabular}

Thrombocytopenia.

tWeight loss and night sweats.

$0 \cdot 5 \times 10^{9} / 1$ to $\left.1 \cdot 2 \times 10^{9} / 1\right)$. Twenty were asymptomatic (Centers for Disease Control stages II or III $)^{7}$ but most $(14 / 20)$ had fewer than $0.5 \times 10^{9} / 1 \mathrm{CD} 4+$ peripheral blood lymphocytes.

\section{Discussion}

There is clearly a demand for a service in an open clinic setting providing rapid HIV-I antibody results. Public awareness of the long incubation period of AIDS is growing, and individuals may wish to determine whether their lifestyle, perhaps a few years previously has led to them acquiring HIV infection.

Also, they may want to avoid putting their loved ones at risk of HIV infection if they are carrying the virus; on the other hand, they may wish to dispense with safe sex practices when the partners in a monogamous relationship are both HIV negative. Knowledge of HIV state may be an important issue before embarking on pregnancy. In addition, there is an increasing perception that early chemotherapy against the virus itself ${ }^{89}$ or against opportunistic infections (Pneumocystis carinii pneumonia, for example ${ }^{10}$ ) may now provide substantial prophylaxis, and therefore the knowledge of HIV state and CD4 cell counts is medically useful. Finally, some members of groups at risk may wish to volunteer for controlled trials, not to benefit themselves but to improve treatment of HIV in general. We saw examples of all of these trends in the clinic and conclude that no stereotype exists for the person who wants to be tested for HIV antibodies. Thus, an open service such as this should be freely available to meet these needs.

When we discussed our plans for establishing this clinic colleagues from other institutions were sceptical as to whether we could provide accurate results and suggested that counselling would be curtailed. For the first point, our results show that all patients who were given an initially reactive result had their results confirmed within 48 hours. Five patients had an equivocal result, and for all five it was possible to issue a definitive negative report within 48 hours. All patients given reactive or equivocal results had been specifically prepared for these eventualities in the pretest counselling.

The compression of pretest and post-test counselling into one day around a specified time has proved a challenge. It is striking that of the 565 patients who attended in the first year, 561 proceeded to have the HIV-I antibody test-an uptake of $99 \%$. This compares with previous reports of $50 \%$ and $75 \%$ 
uptake. ${ }^{112}$ Some of this difference may be due to the fact that the patients attending the clinic have already had some counselling on the telephone, and a minority may also have had a more formal counselling session in the counselling unit. Another possible explanation might be a change in public perception of the advantages of an HIV test in the four years since previous reports were published.

Most of the demand for the service came from outside our health district but from within London. The individuals using this service were all self referrals and had perceived themselves to have been at risk for contracting HIV. Nevertheless, it is interesting to note that the overall seroprevalence of $3.9 \%$ is comparable to the report of $5 \cdot 8 \%$ from similar freestanding clinics in the United States, ${ }^{13}$ where the population seroprevalence is thought to be much higher. The prevalence reported here is also similar to the $5 \%^{12}$ but lower than the $11 \%{ }^{14}$ reported from self referrals to departments of genitourinary medicine in London for HIV testing in 1987, at the time of an intense media campaign on the possible spread of HIV in the heterosexual population. In addition, a recent report of 15850 voluntary referrals tested in France gave an overall seroprevalence of $4 \cdot 8 \%$ (A Cavalier et al, abstract FC620, sixth international conference on AIDS, San Francisco, 1990). A different group, possibly those with lower sexual risk, might choose to attend a service not attached to a department of genitourinary medicine, but we have no data to support this and confirm that the highest seroprevalence remains in the categories of homosexual risk or risk from intravenous drug use. Our seroprevalence for homosexual men (12\%), intravenous drug users $(20 \%)$, and male heterosexuals $(1 \%)$ correlate well with the corresponding rates of $12 \cdot 4 \%, 17 \%$, and $1.8 \%$ that Cavalier $e t$ al, reported from France. It is important to emphasise the young age of the population using the service-the overall median age was 28 years and the median age of the 22 who tested positive was 29 years.

Most of those who had detectable antibodies to HIVI were asymptomatic, and although most of these had CD4 cell counts below $0.5 \times 10^{9} / 1$, they had had their HIV infection diagnosed relatively early. During follow up these asymptomatic patients have been able to discuss the timing of medical intervention in the light of serial CD4 cell counts, which have recently been shown to have prognostic value, although not on an individual basis. ${ }^{6}$ They have been able to discuss the implications of the data suggesting that asymptomatic patients with $\mathrm{CD} 4$ cell counts below $0 \cdot 5 \times 10^{\%} / 1$ should be offered treatment with zidovudine because it offers a means of prolonging the asymptomatic phase of HIV infection $^{8}$ despite the lack of information on whether this early intervention will prolong overall survival or on whether it will lead to clinically important zidovudine resistant HIV. ${ }^{15}$ They have also been able to discuss primary prophylaxis for $P$ carinii infection before CD4 cell counts fell below $0 \cdot 2 \times 10^{9} / 1$. Although there are no prospective data on the benefits of primary prophylaxis for $P$ carinii infection for asymptomatic patients, there are clear recommendations that it should be introduced for patients with CD4 counts below $0.2 \times 10^{9} / .^{16}$ These are based on the success of primary prophylaxis for patients with Kaposi's sarcoma ${ }^{10}$ and the recognition that the risk of developing $P$ carinii pneumonia rises considerably once the CD4 count falls below this level. ${ }^{17}$ The benefits to asymptomatic patients of discovering latent or unrecognised infections have been difficult to assess rigorously.

While the debate continues as to whether the medical advantages for most asymptomatic individuals discovering that they are HIV positive outweigh the disadvantages, the demand for the same day testing clinic continues to increase. We are considering extending testing to a second day in the week to cope with this demand.

We thank Anthony Timms and Margarita Bofill for the CD4 cell counts; Kathy Downes and Heather Charman for the HIV assays; and Peter Scragg, Lorraine Campbell, Greta Depledge, and Hazel Adams for coding and data entry. Financial support for data analysis was provided by North East Thames Regional Health Authority.

1 Schwartz JS, Dans E, Kinosian BP. HIV test evaluation, performance and use. FAMA 1988;259:2574-9.

2 Moss AR, Bachetti P. Natural history of HIV infection. AIDS 1989;3:55-61.

3 Lo B, Steinbrook RL, Cooke M, Coates TJ, Walters EJ, Hulley SB, Voluntary screening for human immunodeficiency virus (HIV) infection: weighing the benefits and the harms. Ann Intern Med 1989;110:727-33.

4 Squire SB, Johnson MA. Early diagnosis of HIV infection. Br I Hosp Med $1990: 44: 9$.

5 Volberding P. HIV infection as a disease: the medical indications for early diagnosis. F Acquired Immune Defic Syndr 1989;2:421-5.

6 Phillips AN, Lee CA, Elford J, et al. Serial CD4 lymphocyte counts and the development of AIDS. Lancet 1991;337:389-92.

7 Centers for Disease Control. Revision of the CDC surveillance case definition for acquired immunodeficiency syndrome. MMWR 1987;36(suppl 1): 3-15

8 Volberding P, Lagakos SW, Koch MA, et al. Zidovudine in asymptomatic human immunodeficiency virus infection; a controlled trial in persons with fewer than $500 \mathrm{CD} 4$ positive cells per cubic millimetre. $N$ Engl $\mathrm{f} \mathrm{Med}$ 1990;322:941-9.

9 Fischl MA, Richman DR, Hansen N, et al. The safety and efficacy of zidovudine (AZT) in the treatment of subjects with mildly symptomatic human immunodeficiency virus type 1 (HIV) infection. Ann Intern Med 1990;112:727-37.

10 Fischl MA, Dickinson EM, La Voie L. Safety and efficacy of sulfamethoxazole and trimethoprim chemoprophylaxis for Pneumocystis carinii pneumonia in and trimethoprim chemoprophyl

11 Green J, Miller D. In: Gottlieb MS, ed. Current topics in AIDS. Vol 1. Chichester: Wiley, 1987:287-302.

12 Sonnex C, Petherick A, Adler MW, Miller D. HIV infection: increase in public awareness and anxiety. BMF 1987;295: 193-5.

13 Centers for Disease Control. Publicly funded HIV counselling and testing. United States, 1985-1989. MMWR 1990;39:137-40.

14 Beck EJ, Cunningham DG, Moss VW, Harris JRW, Pinching AJ, Jeffries DJ HIV testing: changing trends at a clinic for sexually transmitted diseases in London. BMF 1987;295:191-3

15 Larder BA, Darby G, Richman D. HIV with reduced sensitivity to zidovudin (AZT) isolated during prolonged therapy. Science 1989;243:1731-4.

16 Murphy FA, Curran JW. Guidelines for the prophylaxis against Pneumocystis carinii pneumonia in persons infected with human immunodeficiency virus. MMWR 1989:38(suppl 5):1-9S

17 Masur H, Ognibene FP, Yarchoan RY, et al. CD4 counts as predictors of opportunistic pneumonias in human immunodeficiency virus infected opportunistic pneumonias in human imm
individuals. Ann Intern Med 1989;111:223-31.

(Accepted 27 March 1991)
What is the smallest gauge of intravenous peripheral cannula that should be used for blood transfusions?

There is no rule on which to base an answer to this question. Events in which transfusion is required vary from the traumatised and exsanguinated adult to the tiniest anaemic preterm infant. In the first event almost no cannula is large enough; in such a setting trauma specialists may even tie the tubing of a giving set directly into a large vein using a cut down procedure. In the second event almost no cannula is too small; transfusions of $10 \mathrm{ml}$ or $15 \mathrm{ml}$ will run through a 24 gauge Teflon coated cannula in well under one hour without the aid of an infusion pump.
The physical rule governing the rate of laminar flow of a fluid through a cylindrical pathway is $\mathrm{v}=\pi \mathrm{pr}^{4} / 8 \xi \mathrm{l}$, where $\mathrm{p}$ is the pressure difference along the pathway, $r$ is the radius, $\xi$ is the coefficient of viscosity of the fluid, and $l$ is the length of the pathway. The rate of flow increases with the fourth power of the radius, so that even a small increase in the radius is of great benefit if high flow rates are required. As the rate is inversely proportional to length, short cannulas have a similar but smaller effect. Increasing the pressure is not always advantageous, as this may produce turbulent flow, especially at the cannula outlet. This may disrupt blood cells and encourage platelet deposition.-BARBARA BANNISTER, consultant in infectious and tropical diseases, London 